\title{
Refractive Errors in Children with Intellectual Developmental Disorders Attending Special School in Puducherry
}

\author{
Arthur Dinu Kumar ${ }^{1}$, Ganapathy Kalaiselvi², Selvaraj Vennila ${ }^{3}$ \\ ${ }^{1}$ Department of Ophthalmology, Aarupadai Veedu Medical College and Hospital, Vinayaka Mission \\ Research Foundation, Kirumampakkam, Puducherry, India. ${ }^{2}$ Department of Ophthalmology, Aarupadai \\ Veedu Medical College and Hospital, Vinayaka Mission Research Foundation, Kirumampakkam, \\ Puducherry, India. ${ }^{3}$ Department of Optometry, School of Allied health Science, AVMCH Campus, VMRF, \\ Kirumampakkam, Puducherry, India.
}

\section{ABSTRACT}

\section{BACKGROUND}

Vision plays a major role in acquiring various skills as the child grows, like understanding facial expression and communication. In children with intellectual disabilities, vision problems would further impair their social and learning activities. We wanted to assess the refractive errors in children with intellectual developmental disorders attending a special school.

\section{METHODS}

This was a cross sectional study which included the children aged between 4 and 15 years with intellectual developmental disorders (earlier referred as mental retardation) who were attending a special school. After taking permission from the school director and consent from parents or guardian who accompanied the child, detailed ocular examination was done. Visual acuity assessment and cycloplegic retinoscopy of all children was also done and spectacles were prescribed. Children requiring further evaluation were referred to base hospital.

\section{RESULTS}

A total of 50 children with mental retardation were enrolled. There were 28 (56\%) male and $22(44 \%)$ female children in the study. 40 (80\%) children had ocular problems, 28 (56\%) children were unable to cooperate for visual assessment. Refractive error was the commonest ocular disorder noted in 22 (55\%) children followed by strabismus in 7 (17.5\%) children and nystagmus in $5(12.5 \%)$ children. Among the refractive errors, myopia was noted in $64.1 \%$ of children, followed by astigmatism and hypermetropia in $23.1 \%$ and $12.8 \%$ children respectively.

\section{CONCLUSIONS}

The ocular abnormalities noted among these special children increases with the severity of the disability along with worsening of their communication and cooperation. Early identification and correction of the treatable visual problems would benefit these children in their training, communication and thus helps in their rehabilitation.

\section{KEY WORDS}

Intellectual Developmental Disorders, Refractive Error, Myopia

\author{
Corresponding Author: \\ Ganapathy Kalaiselvi, \\ Associate Professor, \\ Aarupadai Veedu Medical College and \\ Hospital, Vinayaka Mission Research \\ Foundation, Kirumampakkam-607403, \\ Puducherry, India. \\ E-mail: kalaiselvirain@gmail.com
}

DOI: $10.14260 /$ jemds/2020/148

Financial or Other Competing Interests: None.

How to Cite This Article:

Kumar AD, Kalaiselvi $G$, Vennila $S$. Refractive errors in children with intellectual developmental disorders attending special school in Puducherry. J. Evolution Med. Dent. Sci. 2020;9(09):682686, DOI: 10.14260/jemds/2020/148

Submission 16-12-2019,

Peer Review 03-02-2020,

Acceptance 11-02-2020,

Published 02-03-2020.

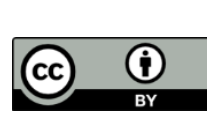




\section{BACKGROUND}

Visual problems are more commonly seen among children with intellectual disabilities.[1-5] Vision plays an important role in acquiring skills like language, hand eye coordination, without sufficient visual acuity children are limited in their learning experiences and difficult to achieve the developmental milestones. Among the children with intellectual developmental disorders (IDD), (previously referred to as mental retardation or intellectual disability) [6] vision plays a major role in their psychosocial development. [7] Any unrecognized ocular - visual abnormality in these children adds on to their already existing limitations in communication, self-care and social skills. Thus the economic burden of the family also increases. Furthermore if a child continues to suffer from visual deficit beyond the age 10-12 years, the plasticity of visual system is lost and the recovery of vision can be limited. ${ }^{[8]}$ The presence of more than one disability has a negative impact on the quality of life. Ocular problems in these children with intellectual developmental disorders (IDD) often go unnoticed as the priorities are given for the primary disability. The assessment of these children with special needs are indeed challenging as they have poor cooperation. $[1,3,7]$ Their assessment requires patience, various range of assessment instruments according to their communication abilities.

The prevalence of IDD is around 1\% in high income countries and $2 \%$ in low and middle income countries in a meta-analysis study.[9] In India according to the census conducted in 2011, 26.8 million people are suffering from one or the other type of disability, which is $2.21 \%$ of the total population.[10] Out of the disabled persons $6 \%$ are with intellectual developmental disorders (IDD). Among the age group of 0 to 19 years with disability $8 \%$ of the children are having intellectual developmental disorders (IDD). [10] Though the magnitude of the problem is huge, the affected people are underserved due to the lack of awareness about their various interrelated problems, even among their parents and the care givers. [3]

Familiar environment and careful assessment are necessary to recognize ocular disorders in these children with special needs.[2,7] Frequently these children with special needs cannot communicate their problems or symptoms. They may receive various interventions through their school, but without correcting the visual problems the interventions might not give appropriate improvement and help in them getting trained in various skills necessary for life support. Thus the aim of the present study was to assess the refractive errors in these children with special needs who were enrolled in a special school and to identify the treatable causes of their visual problem.

\section{METHODS}

The Institutional Ethical Committee approved the study. The director of the special education school for mentally retarded children had been informed about the ocular examination of the children and permission was obtained from him for the examination. The examination process was explained to the parent or guardian accompanying the children. Those children whose parents did not give consent for the examination were excluded from the study. Written informed consent was taken from the parent or guardian who accompanied the child.

As a purposive sampling we took a special education school for mentally retarded (IDD) children in Puducherry for this study. A total of 50 children withintellectual developmental disorders (IDD) in the age group of 4-15 years attending a special school in Puducherry were examined by a team of optometrist, clinical psychologist and ophthalmologist. Complete ocular examination was done. Ocular problems were identified and categorized according to the intelligent quotient. The diagnosis of mental retardation was based on Diagnostic and Statistical Manual of Mental Disorders (DSM)-4 IQ range diagnostic criteria and the intelligence quotient was assessed using Binet-Kamat method by the accompanying clinical psychologist.[11]

Age, sex, residential address, ocular complaints, and previous refractive error if any were noted. Visual acuity was tested using Snellen's Chart, SG chart, Picture chart and Cardiff card were used according to their ability to interpret. Ocular examination was done on torch light, Ocular motility was tested using alternate cover uncover test. Cycloplegic refraction was done. Fundus examination was done in all students. Glasses were prescribed to all children having visual acuity less than $6 / 6$ and according to the retinoscopy values for those who were unable to cooperate for vision testing.

\section{Statistical Analysis}

The data was entered using an excel sheet and analyzed using SPSS software version 22. The data was expressed using descriptive statistics.

\section{RESULTS}

A total of 50 school children, aged 4 to 15 years, with intellectual developmental disorders (IDD) in special education schools were examined. 40 (80\%) children had ocular problems. Of the 50 students, 28 (56\%) were male and $22(44 \%)$ were female. Their age distribution is shown in Figure-1. Out of the 15 students with mild mental retardation (IDD), 11 (73.3\%) had ocular problems. Out of 15 students having moderate mental retardation (IDD), 13 (86\%) had ocular problems. Out of the 17 with severe mental retardation (IDD), 14 (82.3\%) had ocular problems and out of 3 with profound mental retardation (IDD) two $(66.7 \%)$ had ocular problem as shown in table -1 .

The distribution of the students having ocular problems is presented in figure - 2. Refractive error noted in 22 kids (55\%) was the commonest ocular problem followed by Strabismus in 7 (17.5\%), nystagmus in 5 children $(12.5 \%)$, corneal opacity in 2 children (5\%). Retinitis pigmentosa $(2.5 \%)$, microphthalmia $(2.5 \%)$, corneal dystrophy $(2.5 \%)$, optic atrophy $(2.5 \%)$ were seen in one child each. Out of the 
profound mentally retarded children one of the children had optic atrophy and the other child had microphthalmia.

Visual acuity was tested using Snellen's Chart, SG chart, Picture chart and Cardiff card were used according to their ability to interpret as in figure-3. Twenty-eight children (56\%) were unable to cooperate for the visual acuity assessment by any of the above-mentioned charts. Retinoscopy values of them were considered for their refractive error correction. Refractive error was seen in 22 students (55\% of ocular problem). Of them refractive error was present in both eyes in 17 students $(77.3 \%)$ whereas 5 children $(22.7 \%)$ had in one eye only. Among 100 eyes of 50 students 39 eyes had refractive error. The most common type of refractive error was myopia in 25 (64.1\%) eyes, followed by astigmatism in $9(23.1 \%)$ eyes and hypermetropia in 5 $(12.8 \%)$ eyes as shown in figure -4 .

Of the $7(17.5 \%)$ kids with strabismus $4(57.1 \%)$ had exotropia and $3(42.9 \%)$ had esotropia. Spectacles were prescribed to the $22(55 \%)$ children with refractive error, among them 19 of them were first time users, while 3 kids had their refractive error corrected. Rest of the children with ocular problems were referred to base hospital for further evaluation and management.
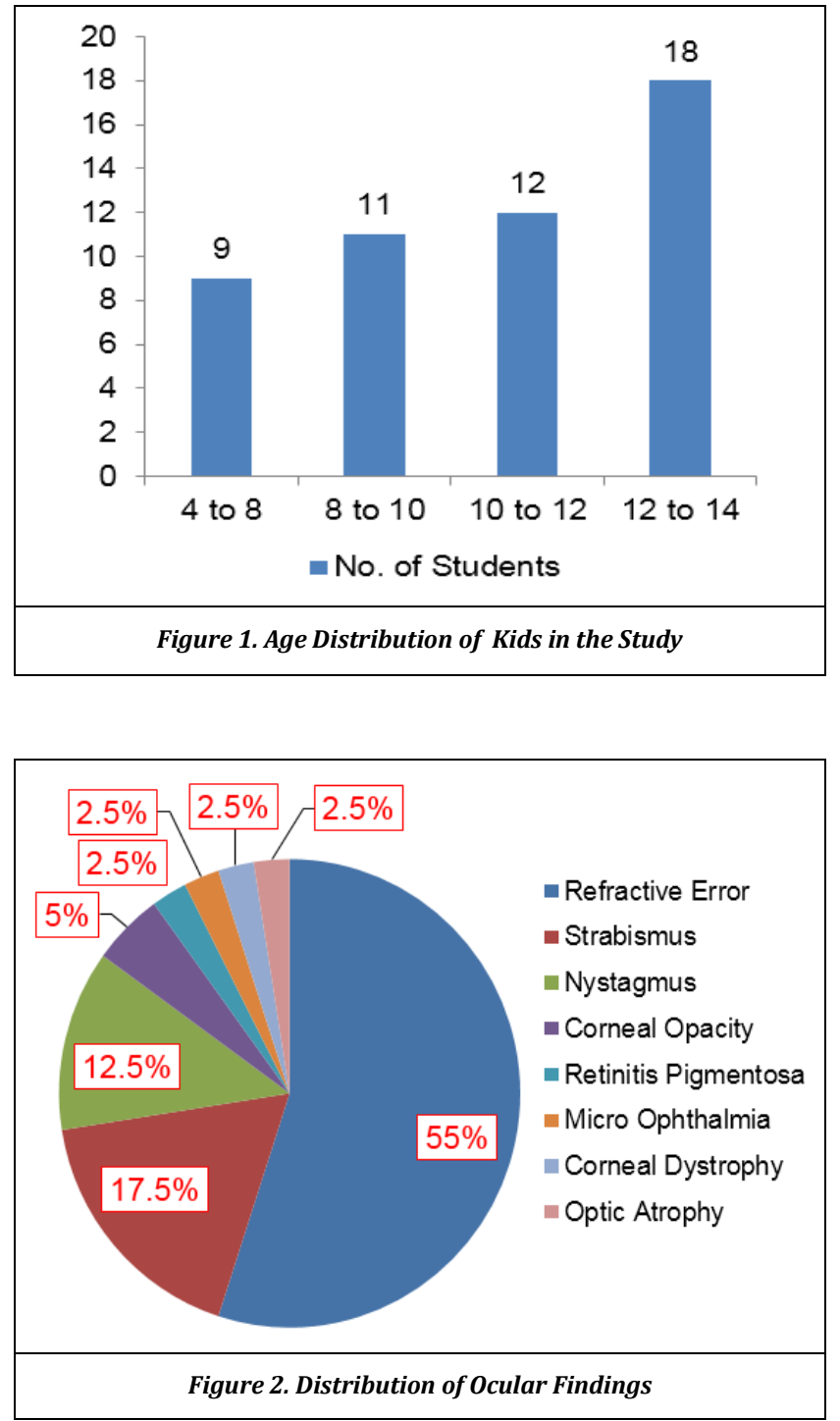
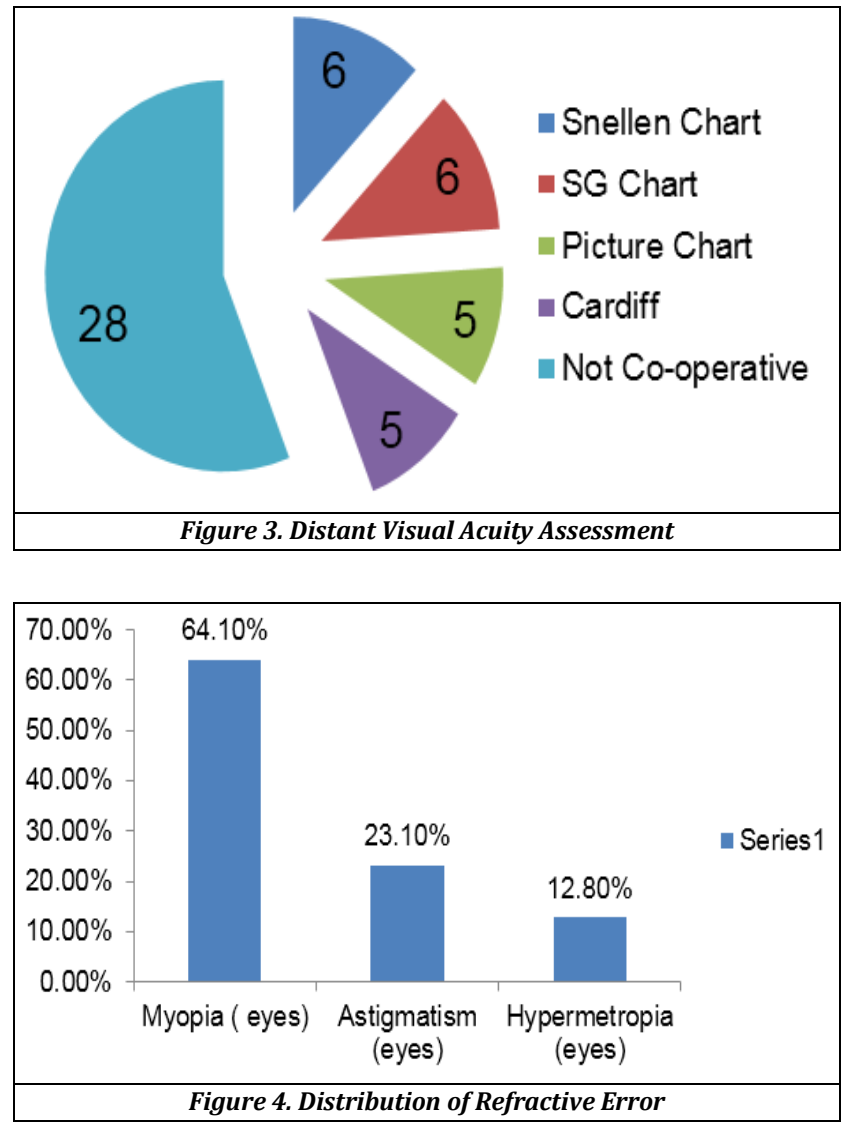

\begin{tabular}{|c|c|c|}
\hline Mental Disability/ IDD (I.Q.) & \begin{tabular}{|c|} 
Total No. of \\
Kids
\end{tabular} & $\begin{array}{c}\text { No. of Students with Ocular } \\
\text { Morbidity }\end{array}$ \\
\hline Mild ( $50-69)$ & 15 & $11(73.3 \%)$ \\
\hline Moderate (35-49) & 15 & $13(86.7 \%)$ \\
\hline Severe $(22-34)$ & 17 & $14(82.3 \%)$ \\
\hline Profound $(<20)$ & 03 & $2(66.7 \%)$ \\
\hline Total & 50 & 40 \\
\hline
\end{tabular}

\section{DISCUSSION}

Children with intellectual developmental disorders (IDD) have poor communication skills and hence ocular assessment of these children was a challenge. Out of the 50 children in a special school who were examined $56 \%$ of them were unable to cooperate for the visual acuity assessment while Gogate et al had reported only $2.9 \%$ of the kids were not cooperative.[3] Parents and the care givers cooperated for the kids examination. Sufficient time was devoted for the visual acuity assessment by retinoscopy and the ocular examination for those children who were unable to cooperate for the assessment. The present study found $80 \%$ of the children had ocular problems. Go gate et al in special schools of Pune reported $45.3 \%$ of the children with learning disabilities had ocular disorder[3] and Joshi RS et al in Nagpur reported $51.45 \%$ of children with mental retardation had ocular problems, ${ }^{[12]}$ while in a hospital based special clinics study by Arthur et al in Puducherry had reported $70 \%$ of children withintellectual developmental disorders (IDD)having ocular problems.[13] 
Refractive error (55\%) was the most common ocular problem noted in our study. Go gate et al had reported with refractive error in $27.3 \%$ of their children,[3] Banks found $49 \%$ mentally handicapped children had some form of refractive error, ${ }^{[14]}$ while Ghising $\mathrm{R}$ et al had reported $67.9 \%$ refractive errors among intellectually challenged students in Nepal,[15] and Vora U et al had reported $58.5 \%$ of refractive error among the special children in Oman.[16]

Among the refractive error, myopia was noted in $64.1 \%$, followed by astigmatism in $23.1 \%$ and hypermetropia in $12.8 \%$ in the present study. Similar distribution was reported by Joshi RS et al as $60 \%$ of myopic, $20 \%$ of astigmatic and $20 \%$ hypermetropic refractive errors,[12] while Vora $U$ et al had reported astigmatism in $27.1 \%$ followed by myopia in $24.3 \%$ and hypermetropia in $18.6 \%$ of special kids.[16] Ghising R et al had reported hypermetropia in $50.3 \%$ followed by myopia $24.9 \%$ and astigmatism at $24.8 \%$ of the children studying at special schools of Kathmandu valley.[15]

Strabismus was noted in $17.5 \%$ and nystagmus in $12.5 \%$ of the special children following the refractive error in the present study. Similar observation had been reported by Joshi RS et al among the mild, moderate, severe mentally retarded children. ${ }^{[12]}$ Kalaiselvi et al had reported as $54.5 \%$ of the special kids had refractive error followed by $19.3 \%$ strabismus and $17 \%$ nystagmus at a hospital based study,[17] while Ghising $\mathrm{R}$ et al in Nepal had reported as $67.9 \%$ of refractive error, followed by ocular motility disorders like nystagmus and squint at $10.1 \%$ among the special school children. ${ }^{[15]}$

As the majority of the ocular problems noticed were refractive error and strabismus, they also lead to amblyopia if not treated at appropriate age. These commonly noticed ocular problems belong to treatable cause of visual impairment, treatment at early age would improve their ability to develop their communication skills. [3,7] If these visual problems left untreated beyond age limit of 10-12 years, the plasticity of the visual system would be lost, and the visual recovery would be limited. [8] Also treating them early would prevent the occurrence of amblyopia and would decrease their burden of visual impairment. Thus the need for regular ocular assessment in the special schools as in the regular schools is evident in the present study as stressed in various other studies. $[1,3,7]$

The ocular morbidities were noted to be more with increasing severity of intellectual disability in our study which is similar to Joshi RS et al who reported a significant association between the severity of mental disability and ocular morbidities. Also, it had been noted that the visual disabilities in many of these kids were unaware among their parents and care givers. The intervention programmes then become inappropriate to them as these kids' inattentiveness due to visual problems might be interpreted as their deficit in their intellectual disability that they are poor performers.

Out of all the special kids 55\% of them were given spectacles, which included 19 of them given for the first time. Regular follow up of these kids and their compliance with the spectacles to be stressed among the caregivers and the teachers of the special school.

\section{CONCLUSIONS}

The importance of carrying out suitable tests in a familiar environment with patience would bring out the hidden unrecognized ocular problems among these special kids which would bring down the severity of their visual disability, thereby making a huge difference in their daily activities and communication.

\section{REFERENCES}

[1] Woodhouse JM, Davies N, McAvinchey A, et al. Ocular and visual status among children in special schools in Wales: the burden of unrecognised visual impairment. Arch Dis Child 2013;99(6):500-4.

[2] Das M, Spowart K, Crossley S, et al. Evidence that children with special needs all require visual assessment. Arch Dis Child 2010;95(11):888-92.

[3] Gogate P, Soneji FR, Kharat J, et al. Ocular disorders in children with learning disabilities in special education schools of Pune, India. Indian J Ophthalmol 2011;59(3):223-8.

[4] Welinder LG, Baggesen KL. Visual abilities of students with severe developmental delay in special needs education-a vision screening project in Northern Jutland, Denmark. Acta Ophthalmol 2012;90(8):721-6.

[5] Kaur G, Thomas S, Jindal M, et al. Visual function and ocular status in children with disabilities in special schools of Northern India. J Clin Diagn Res 2016;10(10):NC01-04.

[6] Salvador-Carulla L, Reed GM, Vaez-Azizi LM, et al. Intellectual developmental disorders: towards a new name, definition and framework for "mental retardation/intellectual disability" in ICD-11. World Psychiatry 2011;10(3):175-80.

[7] Salt A, Sargent J. Common visual problems in children with disability. Arch Dis Child 2014;99(12):1163-8.

[8] Taylor D. Normal and abnormal visual development: paediatric ophthalmology. Oxford, UK: Blackwell Science Publication 1997: p. 13-28.

[9] Maulik PK, Mascarenhas MN, Mathers CD, et al. Prevalence of intellectual disability: a meta-analysis of population-based studies. Res Dev Disabil 2011;32(2):419-36.

[10] Disabled Persons in India a Statistical Profile 2016. Social Statistics Division, Ministry of Statistics and Programme Implementation. Government of India. Available from: http://www.mospi.gov.in. [Last accessed 2017 Jan 11].

[11] Kamat V. Measuring intelligence of Indian children. Bombay: Oxford University Press 1967.

[12] Joshi RS, Somani AAK. Ocular disorder in children with mental retardation. Indian J Psychiatry 2013;55(2):1702.

[13] Dinukumar A, Kalaiselvi G, Fredrick M, et al. Burden of visual disability in children with other disabilities. TNOAJOSR 2019;57:8-11. 
[14] Bankes KJL. The ophthalmologist's role in multidisciplinary assessment of developmentally handicapped children. Br J Ophthalmol 2006;90:1297303.

[15] Ghising R, Shakya S, Rizyal A, et al. Prevalence of refractive error in mentally retarded students of Kathmandu Valley. Nepal Med Coll J 2007;9(4):262-5.
[16] Vora U, Khandekar R, Natrajan S, et al. Refractive error and visual functions in children with special needs compared with the first grade school students in Oman. Middle East Afr J Ophthalmol 2010;17(4):297-302.

[17] Kalaiselvi G, Kumar D. Ocular disorders in children with learning disabilities in a tertiary Hospital, Pondicherry. Indian J Clin Exp Ophthalmol 2018;4(3):347-51. 